\title{
The forest frontier in the Global South: Climate change policies and the promise of development and equity
}

\author{
Maria Brockhaus $\mathbb{D}$, Monica Di Gregorio, Houria Djoudi, \\ Moira Moeliono, Thuy Thu Pham, Grace Y. Wong
}

Received: 10 October 2020/Revised: 28 April 2021 / Accepted: 5 July 2021/Published online: 3 September 2021

\begin{abstract}
Halting forest loss and achieving sustainable development in an equitable manner require state, nonstate actors, and entire societies in the Global North and South to tackle deeply established patterns of inequality and power relations embedded in forest frontiers. Forest and climate governance in the Global South can provide an avenue for the transformational change needed-yet, does it? We analyse the politics and power in four cases of mitigation, adaptation, and development arenas. We use a political economy lens to explore the transformations taking place when climate policy meets specific forest frontiers in the Global South, where international, national and local institutions, interests, ideas, and information are at play. We argue that lasting and equitable outcomes will require a strong discursive shift within dominant institutions and among policy actors to redress policies that place responsibilities and burdens on local people in the Global South, while benefits from deforestation and maladaptation are taken elsewhere. What is missing is a shared transformational objective and priority to keep forests standing among all those involved from afar in the major forest frontiers in the tropics.
\end{abstract}

Keywords Climate governance - Forest frontier · Inequality $\cdot$ Maladaptation $\cdot$ Politics $\cdot$ REDD +

Supplementary Information The online version contains supplementary material available at https://doi.org/10.1007/s13280021-01602-1.

\section{INTRODUCTION}

Tropical forests and lands are highly visible on today's political agendas and are being claimed for a myriad of global, national, and local interests linked to timber, biomass resources, and the production of commodities such as soy, oil palm, and pulp and paper. They are also the scene of 'sustainable' and low emission development, poverty reduction, conservation, and 'green' growth (Redclift 1997; Scheidel and Sorman 2012; Seymour and Busch 2016). These often conflicting interests and ideas shape forest lands in the Global South as locations where natural environments are turned into resource and commodity frontiers (Kroeger and Nygren 2020). Here, government authorities, private sector actors, conservationists, communities, environmental defenders, and other members of civil society execute their agency and negotiate divergent interests. Yet, there are power imbalances among these actors, often to the disadvantage of local people and environments (Curtis et al. 2018; Peluso and Vandergeest 2020). Under these conditions, inequality is reinforced, produced, and reproduced in the access to and benefits from these forest lands in the Global South. Never the result of single, distinct factors but the outcome of intersections of different social locations, power relations, and experiences (Hankivsky 2014), inequality is both part of the local and global processes and outcomes (Newell 2005).

Forest-based climate change adaptation and mitigation are the most recent additions to this long list of interests and ideas over forests and forest lands in the Global South, with carbon and non-carbon benefits as tangible and intangible commodities. Within the literature, there is concern that with the implementation of new forest and climate governance tools, unsustainable exploitation and 
associated inequalities will simply continue or even be aggravated (Lund et al. 2017; Dawson et al. 2018), despite ambitions and commitments to the contrary (see, for example, the New York Declaration of Forests, the Sustainable Development Goals, and the Paris Agreement). As scholars argue, political transformational change is required for forest and climate governance to break with a history of deforestation, failed adaptation, and unequal development (Brockhaus and Angelsen 2012; Scoones et al. 2015; Temper et al. 2018; Martin et al. 2020). In the context of this paper, we define transformational change as shifts in power relations, discursive practices, and incentive structures that lead away from unsustainable and unjust exploitation in forest frontiers in the Global South (Brockhaus and Angelsen 2012). Examples of transformational change would include changes of the larger social, economic, and regulatory frameworks that govern forests and forest lands, changing global trade and investment patterns, removals of subsidies, and other perverse incentives fueling exploitation, as well as forest industry and sector-specific reforms. At the same time, we observe the persistence of an unsustainable and often unjust business-as-usual (BAU) practice of forest land exploitation. In this paper, we ask what enables and what hinders efforts to break this BAU. The key question we explore is if and how climate governance can positively affect these threatened forest frontiers and facilitate socially and environmentally just transitions away from BAU.

We explore these questions by taking a comparative and multi-level case study approach. The four cases are based on the authors' research conducted over the past two decades linked to four distinct forest and climate change adaptation and mitigation studies. They consist of observations from Southeast Asia, South America, and West Africa and are situated in different temporal, spatial, and socio-economic intersections of forest, climate change, and economic development in the Global South. We adopt a political economy lens to unpack processes of change along the forest and climate change frontier and the embedded processes of resource control and extraction and commodity production. The comparative approach allows us to uncover patterns of business-as-usual and transformational change across the diverse climate and forest frontiers.

The paper is organised as follows. First, we introduce our framework and the 4Is (Institutions, Interests, Ideas, and Information), which we use to examine each of the cases. The discussion builds on the comparative analysis of the cases and identifies power and politics structures that are useful to explain shifts towards transformational change, as well as the lack thereof, namely the persistence of BAU outcomes in global forest governance. We close the paper with a reflection on possible pathways for change.

\section{BACKGROUND AND THEORETICAL FRAMEWORK}

Forest degradation and deforestation in the tropics pose a major challenge to climate change adaptation and mitigation efforts (IPCC 2007). Yet, the underlying problem definition and proposed solutions to this wicked problem are often guided by so-called 'myths' in global forest governance (Delabre et al. 2020). A prominent and persistent myth is the assumption that states and government bureaucracies manage the forest autonomously from largescale economic interests driving deforestation, with an intention to achieve what is best for their country's society. This assumed autonomy of state actors has been questioned for the case of REDD+ in an investigation of the politics of deforestation in the tropics (Di Gregorio et al. 2012). Another popular myth is related to smallholders and the promise that 'participation' in global forest governance will solve deforestation, which ignores power imbalances and implies that local people's land-use practices are the main cause of the problem (Skutsch and Turnhout 2020). Mobility in land use, in the form of shifting cultivation practices and pastoralism, for example, are such 'problematised' practices, justifying efforts to stop what some scholars point out are highly adaptive and sustainable landuse systems in areas with high soil and climate variability (Turner 2011; Djoudi et al. 2013; Bruun et al. 2018; Liao et al. 2020). In recent decades, local environmental activists protesting dispossession set in motion numerous initiatives to halt deforestation and forest conversion at grassroots levels. In parallel, national policies and international programmes to halt tropical deforestation multiplied. However, many of those defending their forests have lost their lives at the hands of business-as-usual interests (Global Witness 2019; Scheidel et al. 2020), and deforestation in the tropics with loss of old-growth forest continues at high rates (Curtis et al. 2018; Harris et al. 2021). Earlier declines in forest loss in Brazil were followed by a very sharp increase in deforestation, accompanied by increasing levels of 'perverse' incentives for activities such as biofuel production in the Amazon largely at the expense of old-growth forests (Ferrante and Fearnside 2020). For global forest governance to foster sustainability in tropical landscapes, those attempting to halt deforestation and enabling local forest-based adaptation will need to recognise the power dynamics and complex interactions resulting in injustices and inequalities within and across communities, societies, and regions (Locatelli et al. 2008; Menton et al. 2020).

Against this backdrop, a political economy in forest and lands in the Global South through the establishment of resource and commodity frontiers becomes visible, with Institutional path dependencies created and reinforced by 
and affecting diverse actors at diverse levels in pursuit of their Interests, favoured or marginalised by specific Ideas and myths and further honed by available or lacking Information and transparency; what we call the '4Is' (Brockhaus and Angelsen 2012). In our conceptualisation of the forest frontiers, we draw attention to sites in the Global South where climate policy efforts, often combined with promises of sustainable development, green growth, and prosperity meet with powerful BAU interests within already established resource extraction and commodity production frontiers. These assemblages contribute to the construction of new tangible and intangible global resources and commodities, while subsumed within (neo)colonial discourses and legal frameworks. Outcomes of these processes might contribute to global as well as national inequalities, where high-consumption lifestyle demands of the global North as well as those of powerful elites within the country are sustained, while neglecting the livelihood needs of local people not being part of these elites and leaving behind societies in developing countries in terms of achieving progress with the SDGs (Redclift and Sage 1998; $\mathrm{Xu}$ et al. 2020). These frontiers are not politics-free spaces, shaped by an imposed frontier governance. Rather, they can be understood as a (forest) governance frontier (Thaler et al. 2019), in recognition of the role of politics in constructing and transforming frontier spaces and in resisting these transformations. Underlying power structures shape ideational and economic accounts of frontier development linked to control, resource extraction and commodity production. We add to this conceptualisation by further unpacking power and politics in tropical forest frontiers under climate change through a comparative perspective and applying the 4Is framework introduced above to extract shared and differentiated conditions enabling change and/or the continuation of business as usual. In our efforts to avoid an easily over-simplified dichotomy of North-South interests that risks ignoring local agency in the processes of change, and the role of China and other South-South relations in many of our forest frontiers, we pay particular attention to the dynamics and interactions among different international, national, and local actors over time, the inequalities in this process and the outcomes, and the diversity of benefits and burdens generated in each of the following cases. We investigate to what extent we see shifts in power and discursive practices, and incentive structures with the introduction of climate change policies and programmes in the frontiers, what elements of BAU continue to remain across cases and what this means for sustainable and fair forest frontiers (Fig. 1).

\section{MATERIALS AND METHODS}

For the purpose of this paper, the authors reviewed their earlier work and case material collected over recent decade(s) in specific research projects related to forests and climate change in the Global South (see Table 1). Detailed descriptions of the cases can be found in the Supplementary information to this paper. The mix of methods used varied across the project-based cases, with mostly qualitative data from interviews, focus group discussions (FGDs), and workshops and policy documents collected and analysed. We conducted disaggregated FGDs (by gender and age in Case 2, and additionally by ethnicity in Case 3) at local levels, and workshops/FGDs at regional and national levels on the intersection of forest, climate, and development policies. For case 3 on forests and adaptation, we used participatory methods to understand

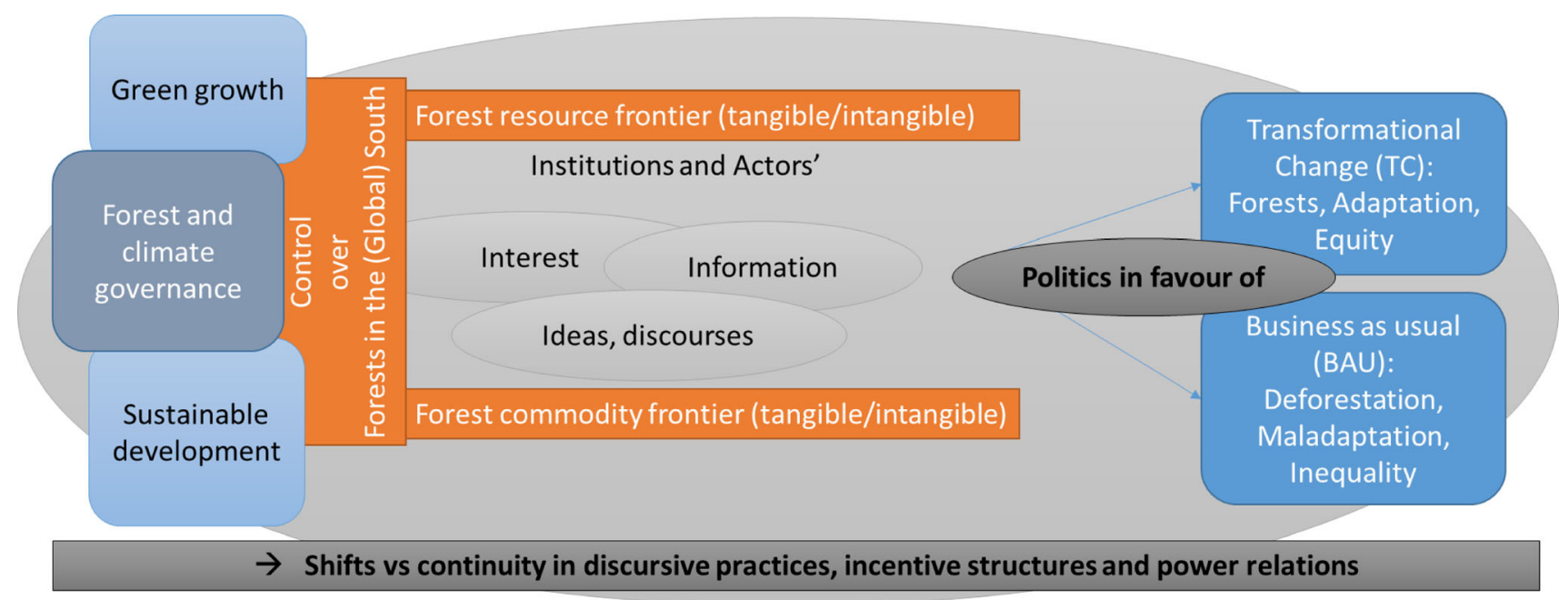

Fig. 1 Politics for change or business as usual (BAU): Local forest frontiers, global calls for climate change policies, and the glocal 4Is (institutions, interests, ideas, and information) 
Table 1 Cases, authors, research projects, and methods applied in different cases

\begin{tabular}{|c|c|c|c|c|}
\hline Case & Brief description & Methods & Geographical scope and actors & $\begin{array}{l}\text { Authors involved in case } \\
\text { study and related research } \\
\text { project }\end{array}$ \\
\hline $\begin{array}{l}\text { 1-REDD+ and } \\
\text { tackling } \\
\text { drivers of } \\
\text { deforestation }\end{array}$ & $\begin{array}{l}\text { Investigation of climate } \\
\text { policy's ability to tackle } \\
\text { deforestation drivers and } \\
\text { related profit, power, and } \\
\text { accountability structures }\end{array}$ & $\begin{array}{l}\text { Qualitative and quantitative } \\
\text { analysis: } \\
\text { Survey and interview data on } \\
\text { discourses and policy } \\
\text { networks at national level } \\
\text { from } 16 \text { countries since } \\
2009 \\
\text { Media analysis } \\
\text { Policy document analysis } \\
\text { Policy network analysis } \\
\text { Qualitative comparative } \\
\text { analysis (QCA) }\end{array}$ & $\begin{array}{l}\text { Bolivia, Brazil, Burkina Faso, } \\
\text { Cameroon, Democratic } \\
\text { Republic of Congo, } \\
\text { Guyana, Ethiopia, } \\
\text { Indonesia, Laos, } \\
\text { Mozambique, Myanmar, } \\
\text { Nepal, Peru, Tanzania, } \\
\text { Vietnam, and Papua New } \\
\text { Guinea } \\
\text { Global review, focus on large } \\
\text { forest-rich } \\
\text { REDD+ countries and } \\
\text { driver structure in global } \\
\text { North and South }\end{array}$ & $\begin{array}{l}\text { Brockhaus, Di Gregorio, } \\
\text { Moeliono, Pham, Wong } \\
\text { Norway, EU, DFID, IKI/ } \\
\text { BMZ funded project: } \\
\text { CIFOR's GCS-global } \\
\text { comparative study on } \\
\text { REDD+ (GCS-REDD+) } \\
\text { (2009-2020) } \\
\text { https://www2.cifor.org/gcs }\end{array}$ \\
\hline $\begin{array}{l}\text { Development, } \\
\text { Forestry, and } \\
\text { Climate Policy }\end{array}$ & $\begin{array}{l}\text { Examination of climate and } \\
\text { social forestry policies in } \\
\text { reflecting logics and } \\
\text { discourses of development } \\
\text { and forest and land } \\
\text { governance control in the } \\
\text { forest frontier }\end{array}$ & $\begin{array}{l}\text { Qualitative analysis: } \\
\text { Policy document analysis } \\
\text { Analysis of interview and field } \\
\text { survey data from } 3 \text { countries } \\
\text { since } 2010 \text { (gender and age } \\
\text { disaggregated), and from } \\
\text { workshops at national and } \\
\text { regional levels }\end{array}$ & $\begin{array}{l}\text { Indonesia, Laos, and Vietnam } \\
\text { Proponents of development, } \\
\text { community forestry, } \\
\text { conservation, and climate } \\
\text { change policies representing } \\
\text { global North, ASEAN, and } \\
\text { national institutions }\end{array}$ & $\begin{array}{l}\text { Wong, Moeliono, } \\
\text { Brockhaus, Pham } \\
\text { Swiss-funded project: } \\
\text { ASEAN-Swiss Partnership } \\
\text { on Social Forestry and } \\
\text { Climate Change (ASFCC) } \\
\text { (2010-2020) } \\
\text { https://www2.cifor.org/ } \\
\text { asfcc/ }\end{array}$ \\
\hline $\begin{array}{l}\text { 3-Adaptation } \\
\text { and a forest } \\
\text { that no one } \\
\text { wants }\end{array}$ & $\begin{array}{l}\text { Analysing with an } \\
\text { intersectional lens to } \\
\text { understand the interaction } \\
\text { of climate and development } \\
\text { politics with vulnerability } \\
\text { dynamics, adaptive } \\
\text { capacity, and strategies of } \\
\text { different social groups } \\
\text { across multiple levels } \\
\text { related to a novel forest } \\
\text { ecosystem frontier }\end{array}$ & $\begin{array}{l}\text { Qualitative analysis: } \\
\text { Policy document analysis } \\
\text { Intersectional analysis of } \\
\text { focus group discussion and } \\
\text { Interview data (gender, age, } \\
\text { ethnic disaggregated) from } 3 \\
\text { communities and at national } \\
\text { and sub-national levels }\end{array}$ & $\begin{array}{l}\text { Mali, Lake Faguibine } \\
\text { Global, national, and local } \\
\text { adaptation policy actors }\end{array}$ & $\begin{array}{l}\text { Djoudi, Brockhaus } \\
\text { EU-funded project: Tropical } \\
\text { Forests and Climate } \\
\text { Change } \\
\text { AdaptationTROFCCA } \\
\text { (2005-2009) } \\
\text { https://www1.cifor.org/ } \\
\text { trofcca/home.html }\end{array}$ \\
\hline $\begin{array}{l}\text { 4- Climate } \\
\text { change } \\
\text { adaptation, } \\
\text { mitigation, } \\
\text { and } \\
\text { development }\end{array}$ & $\begin{array}{l}\text { Analysing power in } \\
\text { adaptation, mitigation, and } \\
\text { development policy } \\
\text { processes and local } \\
\text { implications for forest } \\
\text { frontiers across scales }\end{array}$ & $\begin{array}{l}\text { Qualitative and quantitative } \\
\text { analysis: } \\
\text { Policy document analysis } \\
\text { Analysis of interviews with } \\
\text { climate change policy actors } \\
\text { at three levels of governance } \\
\text { Multi-level policy network } \\
\text { analysis of survey data }\end{array}$ & $\begin{array}{l}\text { Brazil, Indonesia } \\
\text { Multi-level governance actors } \\
\text { across national and two sub- } \\
\text { national levels: in Brazil at } \\
\text { national, state (Mato } \\
\text { Grosso) and municipality } \\
\text { level, and in Indonesia at } \\
\text { national, provincial, (West } \\
\text { Kalimantan) and district } \\
\text { level }\end{array}$ & $\begin{array}{l}\text { Di Gregorio, Brockhaus } \\
\text { ESRC-funded project: } \\
\text { Multi-level governance, } \\
\text { REDD+ and synergies } \\
\text { between climate change } \\
\text { mitigation and adaptation } \\
\text { (2013-2016) } \\
\text { https://gtr.ukri.org/ } \\
\text { projects?ref=ES\% } \\
\text { 2FK00879X\%2F1 }\end{array}$ \\
\hline
\end{tabular}

perceptions and priorities related to the forests and climate change governance across levels of governance. Policy document analysis took place in all cases, mainly based on deductive and inductive coding applied through a critical discourse or institutional theory lens. Cases 1, 2, and 4 also used surveys that allowed for quantitative analysis of actors' position statements, of coalition work, and of policy network structures in the REDD+ and wider land-use policy arenas. Case 2 also utilised social network analysis. Case 1 included longitudinal research, and we repeated the network analysis twice in six countries and completed three rounds of a qualitative comparative analysis (QCA) based on expert assessments in 16 REDD+ countries. In addition, we also conducted a systematic media analysis across nine countries to investigate which actors put forward specific views and positions towards forest-based climate 


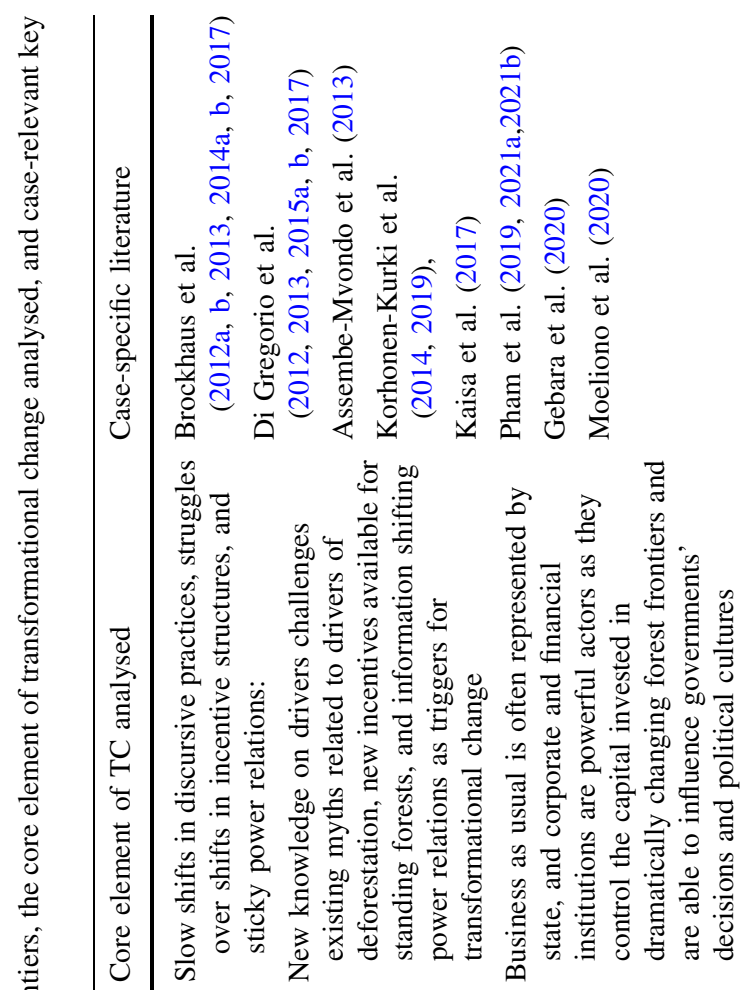

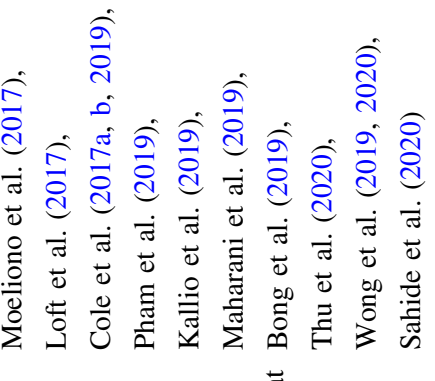

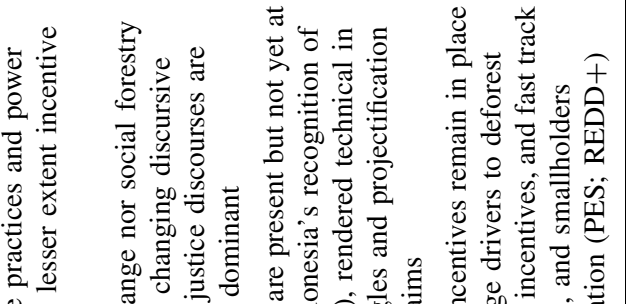

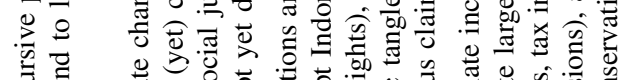

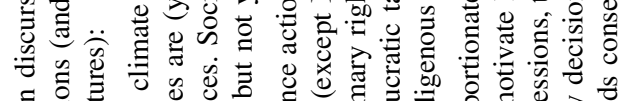

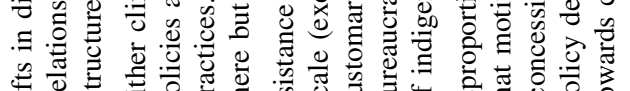

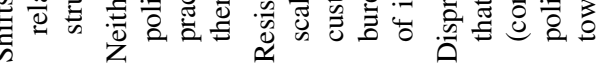
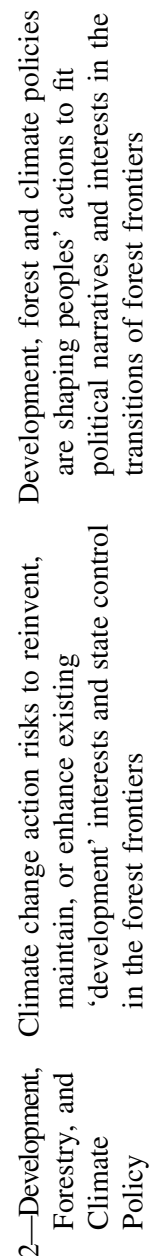


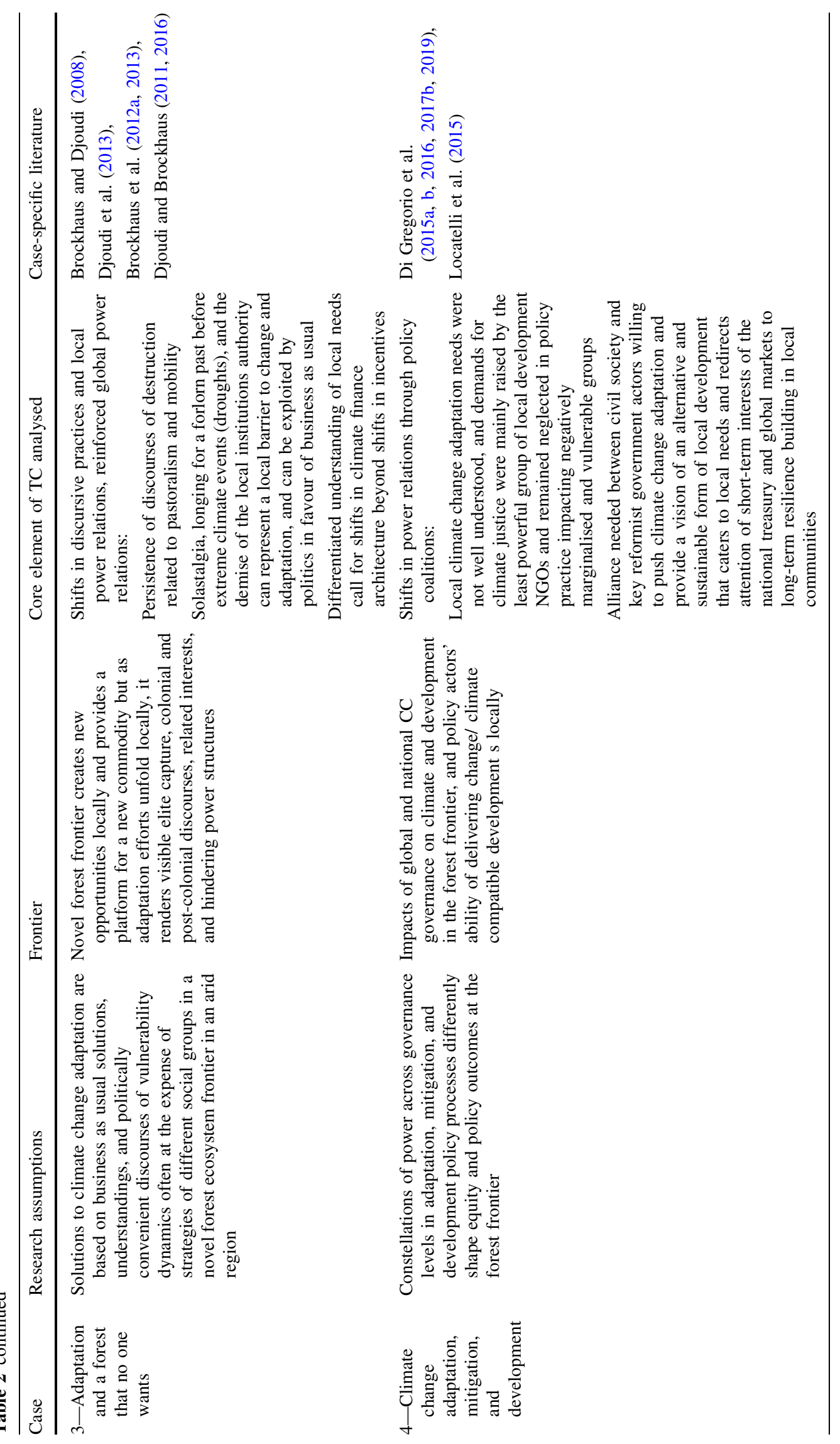

(C) The Author(s) 2021 


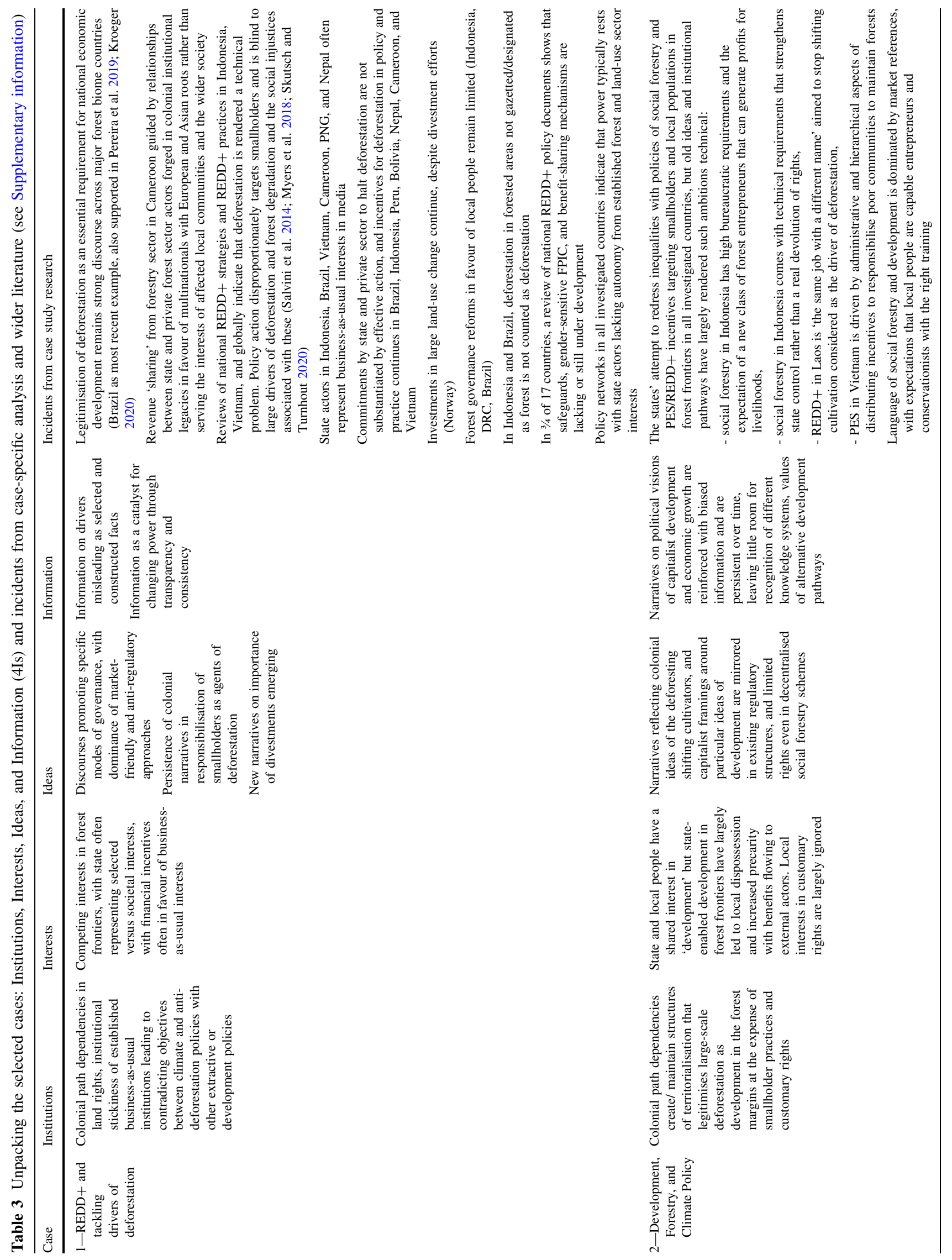




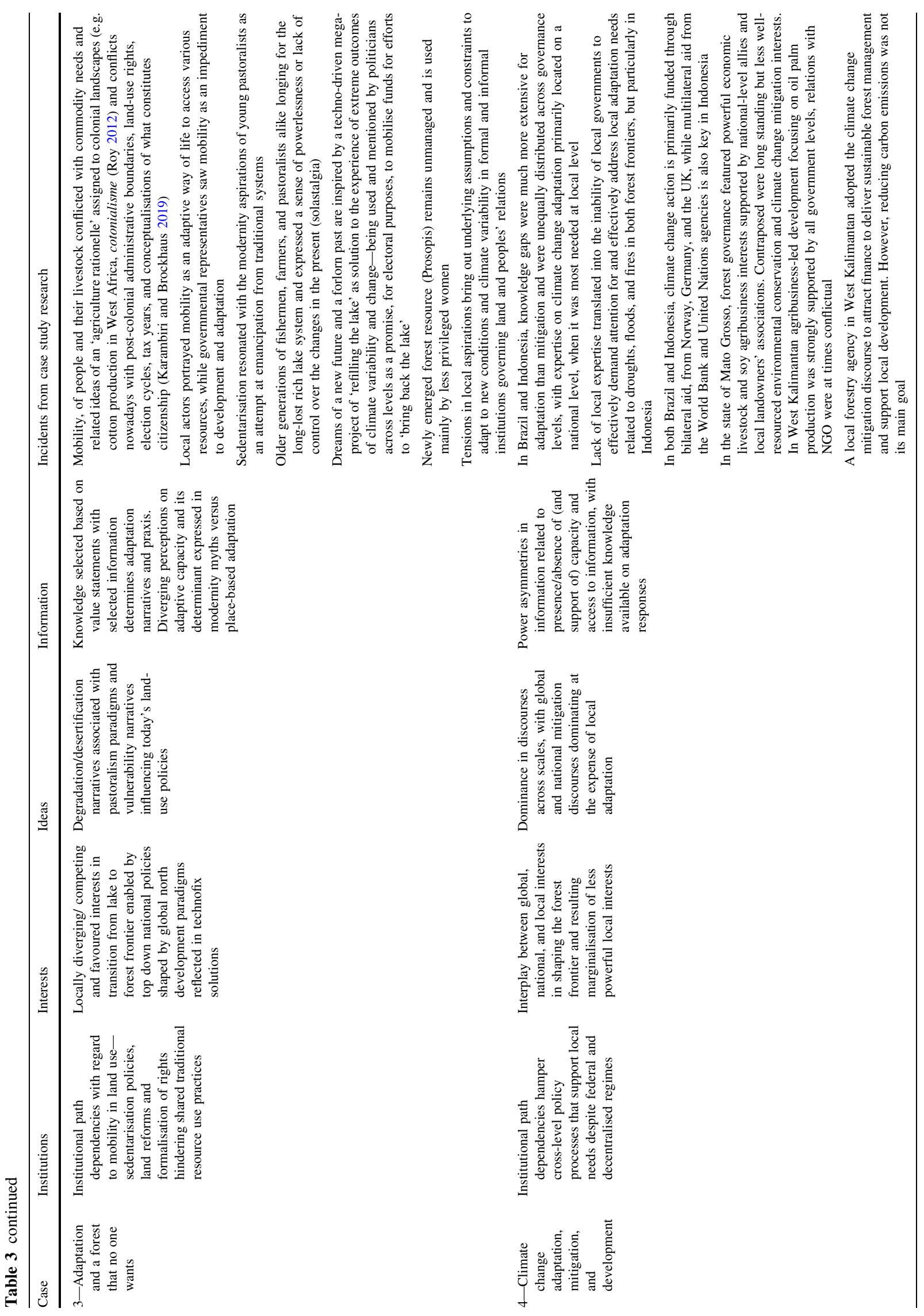


mitigation. For the purpose of this paper, we complemented these case-specific analyses with a review of the wider literature on forest frontiers and transformational change (see Table 1 on methods).

While not all authors collaborated across all research projects and sites (with the lead author as exception), most authors were affiliated to the same international forest research organisation, despite over different projects and periods of time. As authors, in our critical review of discourses, incentives, and power relations, we take an explicitly normative stance through the use of our political economy lens on human-nature relations in the Global South. This positioning draws attention to inequalities embedded in unbalanced power relations, recognises the political nature of socio-economic relationships, and puts ethical consideration centre-stage (Scoones et al. 2015; Klinsky et al. 2017; Clapp et al. 2018). Consequently, business as usual is defined as largely unsustainable and unjust, because it reinforces unbalanced power structures that favour large-scale business interests driving unsustainable practices and facilitating state capture (Rowley et al. 2013), while transformational change is specifically defined as a 'just transition' breaking up pre-existing power structures, reducing power imbalances, and empowering actors that support sustainability. This is not to say that there are no tensions between sustainability and justice, indeed part of the challenge of transformational change is to navigate 'sustainability-equity' tensions (Newell and Mulvaney 2013; Ciplet and Harrison 2020). Hence, our normative stance is reflected in conscious decisions over the choice of what and how we study climate governance and forest frontiers, and for whom. Finally, our long-term presence and collaboration in the selected sites enabled us to take a long-term perspective in the study of change over time.

As Table 1 shows, the cases differ in their specific sites, geographically as well as analytically, with Case (1): a forest mitigation case about REDD+ policy developments and voluntary commitments based mainly on national-level policy analysis across 13 tropical forest countries; Case (2): a development and climate change case drawing on local field data and policy reviews from Indonesia, Laos, and Vietnam; Case (3): an adaptation case anchored in local level research in the area of the Lake Fauibine in Mali, where a forest emerged after a lake system linked to the river Niger dried out. Here, the forest frontier is perhaps the least central to the actors involved in the case that investigates how herders and farmers have adapted over time in this silvo-agro-pastoral system; and Case (4) a case on the integration of adaptation, mitigation, and development efforts in two forest-rich tropical countries, Brazil and Indonesia. All studies are anchored within national policy but reveal important interactions with international and local representation and influences reflected in forest frontiers as discussed in the earlier section.

In each case, we apply the 4Is framework (Brockhaus and Angelsen 2012) and provide insights on how Institutions, Interests, Ideas, and Information as outlined below interact and enable or hamper transformational change:

- Institutional path dependence and stickiness limits change and is often linked to formal power structures (e.g. reflected in colonial land laws and rules, Ministries responsible for natural resources and extractive industries). Institutional change is necessary to break these structures in order to facilitate transformation.

- Interests refer primarily to economic and political interests. When state interests in social and economic welfare of society fall short it is often because of lack of autonomy from interests driving deforestation and degradation (e.g. reflected in profit and rent seeking, fraud, collusion, and corruption). Transformation usually requires a shift in incentive structures and power relations to ensure interests of some key actors change and serve societal needs and ambitions for just transitions.

- Ideas, including ideologies, worldviews, beliefs, and discourse, can reinforce the status quo, as they shape problematisations of environmental impacts and limit the set of choices of what is 'reasonable' or what is put forward as 'the possible' (e.g. benefits from forests for those who effectively and efficiently link local forests to global value chains, versus benefits for those who have moral rights based on equity considerations)

- Information is an important source of power, and data, knowledge, and evidence are often selected, interpreted, and put in context in ways that may reflect the interests of the information provider (e.g. when forest definitions are provided, land-use activities are monitored and rankings are established to distribute climate adaptation finance). Improved access to information or new information can contribute to shift power balances and facilitate change.

Building on our cases, we explore the institutional path dependencies and stickiness embedded in the rules, norms, and policies governing actors and action in the forest frontiers, paying particular attention to the continuation of colonial legacies in post-colonial states. Within this context, we then highlight actors' diverse (material) interests and their ideas and information through an understanding of nature, resources, and commodities in the cases. Here, we pay particular attention to conflicts and collaboration, the role of knowledge and scientific advice as well as accessing and sharing of information and implications for accountability.

In all cases, we mapped the North-South or global dimension, and identified patterns that enable or hinder the 
larger changes needed to move away from inequalities embedded in business as usual resulting from the governance of forest frontiers, be it for adaptation, mitigation, or both and expressed in ongoing deforestation and maladaptation. Maladaptation here is defined as the result of an intentional adaptation policy or measure directly increasing vulnerability for either the targeted and/or for external actor(s) and/or eroding preconditions for sustainable development (Juhola et al. 2016). In each case, we explicitly asked what is missing in the way forest and climate change are problematised and how solutions are presented.

In the comparative and multi-level analysis, we then highlight common and distinctive features of the diverse dynamics of power and politics that became visible through our 4I lens, with issues ranging from expressions of agency and actions of resistance and compliance, specifications of benefits and burdens, to the diverse trajectories of change.

\section{RESULTS: FOUR CASES ON ADAPTATION, MITIGATION, AND DEVELOPMENT IN FOREST FRONTIERS OVER TIME: A 4I APPLICATION}

The four cases selected for the analysis are highly diverse, e.g. with regard to the particular climate change related policies at play, the specific frontier characteristics, and the processes of change taking place (or not). They also feature highly diverse actors and relations between these across different levels and scales. Another main difference between the cases examined here are the underlying assumptions that guided the analysis of the specific case material. Table 2 highlights these diversities and also provides an overview of the literature the original case study produced and on which we build our analysis here.

One core narrative or idea persists across forest frontiers and efforts to halt deforestation and enable development: the suggestion that local actors, particularly smallholders and communities, as well as pastoralists, need to be turned into settled agricultural entrepreneurs to 'develop' and 'modernize' traditional grazing and shifting cultivation systems, which have been blamed as main drivers of deforestation (Dressler et al. 2017; Thu et al. 2020). The 4I analysis of each of the cases as summarised in Table 3, reflect this core narrative, and how it is mirrored in landuse institutions and the interests at play in the Global South (particularly in cases 2 and 3 on development and local adaptation to climate change). Despite evidence to the contrary (Ziegler et al. 2011; Dressler et al. 2017; Bruun et al. 2018), the framing of shifting cultivation and mobile husbandry, of pastoralists and peasants, as responsible for deforestation and degradation has persisted since colonial rule (Thu et al. 2020; Scoones 2021). Such ideas affect till today decisions over what counts as deforestation or does not, and they legitimise which drivers are defined as legal or illegal, measured and reported by whom, how databases are constructed and made accessible, and where are the blind spots-highly political questions as cases 1, 2, and 3 in particular show (see Supplementary information). In addition, as also case 2 highlights, these accounts are then presented as information to justify claims over forests for large-scale production of global commodities such as timber and large-scale agricultural commodities at the expense of local people, as other literature and evidence especially from Southeast Asia highlights (Dove 1983; Doolittle 2003; Dressler et al. 2017; Thu et al. 2020). The colonial discourse of unsustainability of the commons and the deliberate ignorance of customary or traditional farming practices is argued to be partially related to the government's inability to collect revenues from these practices (Doolittle 2003) and is still today embedded in legal frameworks regarding forest and land tenure, as case study 2 with examples from Southeast Asia shows. Hence, one could argue that this institutional path dependency continues throughout the 'post'-colonial state. The interests of former colonial powers and elites are hence firmly anchoured in legal frameworks of 'resource governance' (Assembe Mvondo et al. 2014; Dominguez and Luoma 2020; Astuti 2021). This interest representation leads then to a 'global' forest governance over tropical forests that seems to be more concerned with 'Northern' and capitalist interests representation and control. Demand for food, fuel, and fibre in the Global North, is served through states in alliances with large business interests (Kroeger 2016). Such powerful actors and alliances dominate the frontier dynamics, undermine local agency, and depoliticise forests by rendering the problem of deforestation a technical one (Li 2007; Peluso and Vandergeest 2020). Case 1 in particular highlights these processes, with analysis from Indonesia showing how forest-based mitigation was initially linked to large political change but is now reduced to a technical project (Moeliono et al. 2020), or in Brazil, where interests in keeping forest standing has been shifted over time towards restoration interests linked to intensified biomass production (Gebara et al. 2020). Simultaneously to these power relations of domination and oppression, visible in all cases presented in this paper, power struggles take place within localities, among farmers and herders struggling over access to resources and between state and citizens with diverse and conflicting visions of future development (cases 2 and 3). Power struggles also occur across levels of governance and interest (cases 1, 2, and 4), and across sectors and line ministries competing for limited land and financial resources (cases 3 and 4), including those provided through overseas development aid and climate funds for green growth, sustainable development, and 
mitigation and adaptation actions. Table 3 shows how the 4Is play out in our different cases, and provides incidents from the case study research and the wider literature, while more detailed descriptions of the cases can be found in the Supplementary information to this paper.

\section{COMPARATIVE ANALYSIS OF CHANGE IN THE FOREST FRONTIERS OF THE GLOBAL SOUTH}

The cases provide deeper insights into the many ways of how the forest and climate change agenda is linked to unsustainable development, injustice, and inequality in the forest frontiers of the Global South. The cases are highly diverse in their geographies, spatial, temporal scales, levels of governance investigated, and the types of data analysed. Yet, politics and power are at play in all cases, and the common and differentiated features in the cases will allow us to provide some answers to our central question that guided this investigation. Particularly, we are interested in the understanding under which circumstances climate governance and related policies are able to facilitate transformational change away from a business as usual of inequality with ongoing deforestation and maladaptation.

\section{Unpacking politics and power within the cases}

Case 1 on REDD+ puts into focus North-South relations and the agents and interests playing out in contested forest lands in the tropics. The case highlights how ignoring conflicts between societal and selected interests and the power imbalances present in the forest frontiers weakens efforts to halt deforestation. Private sector actors are often absent from formal REDD+ policy processes but their interests are vitally present, often represented by state actors (Di Gregorio et al. 2013, 2015a, b; Brockhaus et al. 2014b). Yet, while calls for the need to have the 'private sector in the room' are dominant, there are few policy actors calling for regulation of those private sector actors driving deforestation. Meanwhile, the voluntary policy initiatives, such as the New York Declaration of Forests, are a new playing field for these private sector actors (in commodity supply chains, trade, and investment) but fail to reach their own targets, have incoherent reporting (NYDF and Partners 2020) and, with little consequences and accountability, run the risk to distract from the core efforts of REDD+ and other mitigation efforts. It also seems that the politically palatable topic of engaging with the private sector and multi-stakeholder public-private fora has relegated earlier REDD+ ambitions for larger systemic change to small 'projectified' spaces. While power relations seem to remain in favour of business as usual, technological advances, and new information have provided alternatives to political reporting and outdated models of deforestation (e.g. those based on simple indicators of population density). The resulting new discursive practices in policy spaces concerned with deforestation seem to gain traction. In addition, increasingly more transparency along supply chains and within decision making can make it more difficult to defend the politics of deforestation.

Case 2 on development along forest frontiers in Southeast Asia highlights how post-colonial ideas behind the deforestation narratives and associated policies continue to reflect older discourses by responsibilising local communities to stop deforestation and forest degradation despite the significant role of large-scale deforestation drivers and the policies that enable them (Enrici and Hubacek 2016; Ingalls et al. 2018; Cochard et al. 2020). Together with limited devolution and lack of recognition of local rights, this points to state territorialisation with interest to maintain control over lucrative forest resources through a strengthening of the financial, political, and ideological control of remote populations, diverse cultures, and traditional land-use practices.

Case 3 on adaptation in agro-silvo-pastoral systems in West Africa introduces a forest that nobody wants while those using it face challenges related to institutions and discourses. The case highlights how mobility as a highly adaptive strategy is undermined. First 'demonized' in colonial discourses, the same rationales are used by postcolonial state elites to continue pushing for the sedentarisation of pastoralists. The herders and those who were once farmers and fisherman in the former lake region are hampered in adapting locally to the evolving forest ecosystem; narratives of reflooding the area are nurtured through promises of mega-projects' techno-fixes and lead to no or maladaptation, with little or no institutional and financial support for optimising locally adapted strategies. Vulnerability, if not understood and framed in a socio-historical context and designed based on a deeper understanding of local complexities, will continue to result in and shape inequalities. As a tool in climate politics, it is then reduced to a simple means to attract funds for a constructed vulnerability, while, on the other hand, finance to support local adaptation remains missing. The powerful combination of discourses of modernity, longings, and aspirations combined with political and financial (self)-interests leads to maladaptive pathways. The case also shows how local actors seize new opportunities for adaptation and resist discourses and unsustainable promises based on beliefs in techno-fixes to climate change and extreme events.

Through the investigation of the linkages between forest-based mitigation, adaptation, and sustainable development processes, case 4 illustrates that power structures on the forest frontier in the Global South are in fact multi- 
level in nature. Local implementation is strongly impacted by global climate policy processes, rules, and norms, which has an inherent bias toward mitigation action. Further, the constellation of national and sub-national climate mitigation and adaptation interests, together with country specific federal (Brazil) and decentralised (Indonesia) institutional structures interact to shape local outcomes. Simultaneously, local actors use their limited resources, in particular discursive practices, to appropriate and reshape global and national practices. They articulate their interests, predominantly as developmental in nature, but climate change adaptation needs remain poorly addressed, because of a mix of lack of knowledge at lower government levels and lack of support from higher-level institutions. How can the three policy objectives of mitigation, adaptation and sustainable development be effectively integrated to deliver increased resilience to climate change and a sustainable form of development on the forest frontier? A rebalancing of power in policy processes is required to make them more inclusive of diverse local actors' needs and interests.

Common across the four cases, climate action has been often found to be absorbed and lost within development priorities of producing commodity crops for global markets, accompanied by techno-fixes, which are framed as expressions of modernity. Colonial hegemonies are perpetuated as climate action relies on institutional frameworks governing forest lands that newly created nation states have left unchanged with 'independence'. Hence, these post-colonial states with their path dependencies provided fertile grounds for neo-colonialist framings of forest frontiers in the Global South. The adaptation case with the newly emerged forest exemplifies the continuity of 'the colonial' in forest frontiers, as its underlying discourses, institutional legacies, and financial dependencies are reflected even in a place that only recently was turned into a forest frontier.

All the cases pointed to policies that aim to halt deforestation driven by large-scale resource extraction and commodity production on forest frontiers and enable adaptation or enhanced adaptive capacities in the frontiers. Yet, across all cases, these efforts are countered by policies and incentive structures that continue to drive deforestation and maladaptation, often supported by the investments of powerful actors. We also learned about the new commodity of a constructed vulnerability, in contrast to the many lived forms of vulnerability characterised by loss of assets and lack of support to access new ones. Here, vulnerability as commodity, while intangible and constructed by diverse interests often disconnected from the local level, serves national elites in their negotiations over climate finance. Meanwhile, root causes of vulnerability remain unchallenged and an 'Olympics of Vulnerability' continues with rankings and indexes to determine those most vulnerable
(Djoudi et al. 2016; Djoudi and Brockhaus 2016; Barnett 2020). The dominance of business-as-usual trajectories of large-scale deforestation and maladaptation is overwhelming in all cases. Transformational change from these patterns seems out of reach, despite the many well-intended policies and measures that are part of forest and climate change governance in these forest frontiers.

\section{Ways forward to realise just transitions: Or powerful echoes from the past favouring selected interests?}

Across the cases, business as usual in favour of selected interests has maintained dominance over time. While this might not be surprising, the 4I lens we applied to the cases focusses potential leverage points for change in the interplay of diverse factors in the production and reproduction of inequality, in the sharing of benefits and burdens from the changing forest frontiers, and regarding the urgent needs for climate action.

All four cases emphasised how colonial and post-colonial institutional path dependencies enable the continuation of established North-South power relations, with national elites reinforcing these to pursue their own political and economic interests. Discourse shapes these institutions and the related policies and practices as they provide justification for selective priorities and preferences, for e.g. when mitigation matters more than adaptation or when cash crops for global needs are prioritised over local adaptive livelihood and mobility strategies, often summarily dismissed as backwards and environmentally destructive. These findings corroborate much of the literature on political ecology as well as political economy (Dauvergne 1993; Peluso and Lund 2001; Rudel 2007; Forsyth and Walker 2008; McCarthy and Tacconi 2011). In the adaptation case study, we characterise one of the processes that enables this as the set-up of an echo chamber, where the power of a discourse is built on a complex machinery of repeated myths through government speech and officials educated by the very interests that benefit from the practice that follows the myth and echoed by many people whose dreams and ambitions resonate with what is or was promised by the myth. Science and scientists risk to be part of such echo chambers, too, when landscapes are constructed on land-use practices and measurements based on Western forestry ideals and experiences, and expressed through formulas of plantation productivity. Then, science might mute social justice concerns and overpower diverse local land governance practices and voices that call for a critical examination of whose interests are being served by forest management practices, policies, and measures (Ribot et al. 2006; Peluso and Vandergeest 2020). The power of these echo chambers becomes even more audible when local 
farmers and herders describe their own practices as environmentally harmful, sometimes in self-deprecation and other times as a belief.

The cases also highlight what is not problematised and what is missing in framings of climate action along forest frontiers. Across all four cases, the local and the political disappears over time and forest and climate governance in forest frontiers is rendered technical (Myers et al. 2018; Skutsch and Turnhout 2020) and reduced to capacity issues. Instead of engagement with local practices, diverse knowledges, and needs, there is a call for administrative, technical, and financial assistance from the international community. The forest frontier then becomes a depoliticised yet re-colonised site of established North-South relations that date to colonial times in both practices and mindsets.

Power is central to all these processes and to argue, following Foucault (1978), where there is power there is also resistance. 'Power over' - coercive authority-is visible throughout the frontiers presented in our cases, often in favour of selected interests and in ignorance of local realities and needs. Yet, we do also see 'power to'-the productive and generative side of agency-expressed across our cases. The REDD+ case is an example where this constant struggle between interests, coercion, and resistance takes place. Here, we see how, after some initial impulses and calls for broader change, over time climate change actions are seemingly retrofitted into the existing global neoliberal economic order and no longer contribute to nor aim to transformational change. Nevertheless, there is growing acknowledgment that this very order is the source of the problem (Delabre et al. 2020): a barrier to action, a threat to agency's 'power to' change, as we saw in the adaptation and development cases; and a root cause of the problem in the case of REDD+ with global trade and investment patterns driving deforestation beyond tipping points (Galaz et al. 2018). In the adaptation case, an outlier in our initial framing of forest frontiers and related extraction and production of resources and commodities, we argue that vulnerability is also fitted to be part of the current economic order but also reflect constant struggles between the powerful and the powerless. The case demonstrates how a North-South dynamic plays out indirectly in a newly emerged forest, with state actors being occupied by efforts to gain access to and oversight over promised global climate adaptation finance by contributing to the construction of vulnerability as a commodity, yet, while this might indicate a strategy of the post-colonial state to play the existing system, this takes place at the expense of a focus on unpacking local needs and strategies in light of already scarce climate adaptation funding. This struggle and the related trade-offs were also evident in both the REDD+ and the integration cases. In summary, our comparison of different climate policies and interventions across the Global South shows the challenges any type of intervention in forest frontiers faces, and the risk that climate policies actually deny diversity and self-determination at local levels, while also reducing autonomy of postcolonial states from selected global interests in forest frontiers. While we saw differences in the outcomes of these interventions, the overall tendency is that the forest frontiers continue to reproduce inequality, loss of forest, particularly old-growth forests, and maladaptation to the disadvantage of those directly living in or depending on forests-in spite of, and in part because of, climate policy interventions. These findings are corroborated by observations in the wider literature on environmental and climate policy and its outcomes (Dawson et al. 2018; Martin et al. 2020), which also led to questioning the overall contemporary framing of environmental policy and science with its lack of attention to justice, democracy, and inequality (Biermann 2021). What is missing in all cases is a prioritised and powerful interest in keeping trees and forest standing, to the benefit of local populations as an explicit part of just transitions with the aim to reduce existing inequalities, rather than as an afterthought or a desirable side-effect as part of complex-and often dangerous-net calculations (Delabre 2020; Carton et al. 2020).

The comparative analysis presented here is limited as it builds on existing data, rather than as an explicit research design. In addition, this attempt to bring together 20 years of research across the Global South and diverse policy arenas in one research paper also means that we lose some of the deeper insights and nuances from the individual cases. Nevertheless, in applying a wider political economy framework to the analysis, centred on institutional path dependency, interests, ideas, and information, the cases contribute to a better understanding of the processes that enable production and reproduction of inequality within and between South and North, when these forest frontiers are transformed and governed as resource and commodity frontiers.

\section{CONCLUSION}

Across the forest frontiers presented here, initial calls for transformation and restructuring of trade, and of states for effective, efficient, and equitable climate policies are not sufficiently acknowledged and at times have been silenced. We have argued that transformational change requires substantive shifts in incentive structures, discursive practices, and power relations. The cases highlight initial attempts to change incentive structures to keep trees and forests standing and to break with existing myths and 
discursive practices. However, governments are dependent on state revenues to actively steer their own economies, and whether economic development will be sustainable, climate friendly and equitable may depend on their ability to resist the interests that are benefiting from the status quo. Only governments that are open and responsive to civil society and their citizens, are able to gain autonomy from large-scale economic national and international interests, and-allied with other reformist policy actors-might be able to initiate such change. Most often, such alliances require a vibrant civil society, driving, leading, and pushing for change, and being able to hold accountable decision makers to their promises. Thus far, these coalitions for change are not yet sufficiently powerful nor vocal enough to overcome BAU and its echo chambers (Brockhaus et al. 2014a, b). Fall-backs into comfort zones of established (and profitable) power relations put at risk efforts for any lasting change (Barr et al. 2010; Moeliono et al. 2020).

Power structures and institutional environments require nuanced analysis as they cannot be dichotomously organised in 'good' or 'bad' categories. While acknowledging this, the paper aimed to highlight in broad features what seems to serve selected versus societal interests. It also explored what supports today's unsustainable business as usual with ever-increasing emissions and inequalities and pathways that might be transformed for desired changes. As power structures and institutional environments are sticky but also dynamic, established powers are constantly challenged by new ones, and new coalitions and alliances take shape over time, new opportunities and openings arise for transformational change, both through and towards, explicitly equitable as well as effective climate policies. The institutions of our forest frontiers evolve constantly through different historical moments and periods. While the past itself cannot solely be blamed for today's climate inaction, its manifestations over time do not yet allow actors to seize opportunities leading to major institutional change in these forest frontiers. It seems that where the colonial, the post-colonial, the legacies, and the newly created neoliberal institutions have built on each others' power structures to realise their common interests, there is little working in favour of effective and equitable climate action. Colonial models of commerce and governing companies still vibrate through today's vision of what forests are, whom they should serve, and who is considered a risk to efforts that aim to realise these visions. Climate governance in the four forest frontiers presented here, with ambitions to deliver mitigation, adaptation, and development, has not been able to break with established discursive, incentive, and power structures.

Nonetheless, our cases also highlight that climate change policies and measures can contribute to desired changes: with shifts in discursive practices and the incorporation of new or different forms of knowledge; or with shifts in incentives and power structures, e.g. facilitated by increased transparency and accountability; or with policy action that removes incentives and benefits for those driving large-scale deforestations. They can contribute to shift the dynamics of current forest frontiers characterised by resource exploitation and commodity production. There are alternative representations or framings of the deforestation problem and growing diversity of voices at different governance levels that question the divisions of benefits and burdens related to forests. The clamour of alternative discourses and interests across different actors and sectors is a welcome challenge to the dominant techno-scientific and political echo chambers. Yet, while in search of responses to the wicked problems of deforestation and maladaptation in the Global South, forest and climate policies have to address the underlying problem and causes of deforestation and maladaptation rooted in unequal power relations, supported by dominant and persistent narratives and expressed in unjust distributions of benefits and burdens from tropical forests and climate change action. Failing to challenge the wider political and economic system governing forest frontiers and focussing only on symptoms and isolated solutions, as the examined forest and climate cases show, climate policies risk to maintain and produce social and environmental injustices that characterises business-as-usual in forest frontiers in the Global South.

Acknowledgements The authors would like to express their deep gratitude to all informants across the research projects that contributed their time and to our understanding of the specific cases. We would also like to thank our colleagues in the Frontier workshop in Freiburg, Germany in November 2018 for their comments and suggestions. We are grateful for the very helpful reviews and comments on earlier drafts we received for this paper, in particular by Georg Winkel, Natalya Yakusheva, and the two anonymous reviewers. Funding for the case study research was received from the Norwegian Agency for Development Cooperation (Norad), the European Commission (EC), the International Climate Initiative (IKI) of the German Federal Ministry for the Environment, Nature Conservation, Building and Nuclear Safety (BMUB) (case 1), The Swiss Agency for Development and Cooperation (case 2), the European Commission (EC) (case 3), the Economic and Social Research Council (ESRC) (grant number ES/K00879X/1) (case 4). Houria Djoudi, Moira Moeliono, and Pham Thu Thuy were supported by CIFOR's global comparative study on REDD+ and the CGIAR Research Program on Forests, Trees and Agroforestry (CRP-FTA), with financial support from the donors contributing to the CGIAR Fund. Monica Di Gregorio is affiliated with the Centre for Climate Change Economics and Policy (CCCEP) (ESRC Grant Number ES/K006576/1), Grace Wong to the Research Institute for Humanity and Nature (Project Number 14200149), and Maria Brockhaus' time for analysis was co-funded by the Volkswagen Foundation Grant No 96964.

Funding Open access funding provided by University of Helsinki including Helsinki University Central Hospital. 
Open Access This article is licensed under a Creative Commons Attribution 4.0 International License, which permits use, sharing, adaptation, distribution and reproduction in any medium or format, as long as you give appropriate credit to the original author(s) and the source, provide a link to the Creative Commons licence, and indicate if changes were made. The images or other third party material in this article are included in the article's Creative Commons licence, unless indicated otherwise in a credit line to the material. If material is not included in the article's Creative Commons licence and your intended use is not permitted by statutory regulation or exceeds the permitted use, you will need to obtain permission directly from the copyright holder. To view a copy of this licence, visit http://creativecommons. org/licenses/by/4.0/.

\section{REFERENCES}

Assembe-Mvondo, S., M. Brockhaus, and G. Lescuyer. 2013. Assessment of the effectiveness, efficiency and equity of benefit-sharing schemes under large-scale agriculture: Lessons from land fees in Cameroon. European Journal of Development Research 25: 641-656. https://doi.org/10.1057/ejdr.2013.27.

Assembe-Mvondo, S., C.J.P. Colfer, M. Brockhaus, and R. Tsanga. 2014. Review of the legal ownership status of national lands in Cameroon: A more nuanced view. Development Studies Research. https://doi.org/10.1080/21665095.2014.927739.

Astuti, R. 2021. Governing the ungovernable: The politics of disciplining pulpwood and palm oil plantations in Indonesia's tropical peatland. Geoforum. https://doi.org/10.1016/j.geoforum. 2021.03.004

Barnett, J. 2020. Global environmental change II: Political economies of vulnerability to climate change. Progress in Human Geography 44: 1172-1184.

Barr, C., A. Dermawan, H. Purnomo, and H. Komarudin. 2010. Financial governance and Indonesia's Reforestation Fund during the Soeharto and post-Soeharto periods, 1989-2009: A political economic analysis of lessons for REDD+, vol. 52. Bogor: CIFOR.

Benjaminsen, T.A., and P. Hiernaux. 2019. From desiccation to global climate change: A history of the desertification narrative in the West African Sahel, 1900-2018. Global Environment 12: 206-236.

Biermann, F. 2021. The future of 'environmental' policy in the Anthropocene: Time for a paradigm shift. Environmental Politics 30: 61-80. https://doi.org/10.1080/09644016.2020. 1846958.

Bong, I.W., M. Moeliono, G.Y. Wong, and M. Brockhaus. 2019. What is success? Gaps and trade-offs in assessing the performance of traditional social forestry systems in Indonesia. Forest and Society 3: 1. https://doi.org/10.24259/fs.v3i1.5184.

Brockhaus, M., and A. Angelsen. 2012. Seeing REDD+ through 4Is: A political economy framework. In Analysing REDD+: Challenges and choices, ed. A. Angelsen, M. Brockhaus, W.D. Sunderlin, and L. Verchot, 15-30. Bogor: CIFOR.

Brockhaus, M., M. Di Gregorio, and R. Carmenta. 2014a. REDD+ policy networks: Exploring actors and power structures in an emerging policy domain. Ecology and Society. https://doi.org/10. 5751/ES-07098-190429.

Brockhaus, M., M. Di Gregorio, and S. Mardiah. 2014b. Governing the design of national REDD +: An analysis of the power of agency. Forest Policy and Economics. https://doi.org/10.1016/j. forpol.2013.07.003.

Brockhaus, M., and H. Djoudi. 2008. Adaptation at the interface of forest ecosystem goods and services and livestock production systems in Northern Mali. Infobrief 19. Bogor: CIFOR.
Brockhaus, M., H. Djoudi, and H. Kambire. 2012a. Multi-level governance and adaptive capacity in West Africa. International Journal of the Commons 6: 200.

Brockhaus, M., H. Djoudi, and B. Locatelli. 2013. Envisioning the future and learning from the past: Adapting to a changing environment in northern Mali. Environmental Science \& Policy 25: 94-106.

Brockhaus, M., K. Korhonen-Kurki, J. Sehring, M. Di Gregorio, S. Assembe-Mvondo, A. Babon, M. Bekele, M.F. Gebara, et al. 2017. REDD+, transformational change and the promise of performance-based payments: A qualitative comparative analysis. Climate Policy. https://doi.org/10.1080/14693062.2016. 1169392.

Brockhaus, M., K. Obidzinski, A. Dermawan, Y. Laumonier, and C. Luttrell. 2012b. An overview of forest and land allocation policies in Indonesia: Is the current framework sufficient to meet the needs of REDD+? Forest Policy and Economics. https://doi. org/10.1016/j.forpol.2011.09.004.

Bruun, T.B., N. Berry, A. de Neergaard, P. Xaphokahme, I. McNicol, and C.M. Ryan. 2018. Long rotation swidden systems maintain higher carbon stocks than rubber plantations. Agriculture, Ecosystems \& Environment 256: 239-249.

Carton, W., A. Asiyanbi, S. Beck, H.J. Buck, and J.F. Lund. 2020. Negative emissions and the long history of carbon removal. Wiley Interdisciplinary Reviews: Climate Change 11: e671.

Ciplet, D., and J.L. Harrison. 2020. Transition tensions: Mapping conflicts in movements for a just and sustainable transition. Environmental Politics 29: 435-456.

Clapp, J., P. Newell, and Z.W. Brent. 2018. The global political economy of climate change, agriculture and food systems. The Journal of Peasant Studies 45: 80-88.

Cochard, R., D.T. Ngo, and C.A. Kull. 2020. Vietnam's forest cover changes 2005-2016: Veering from transition to (yet more) transaction? World Development 135: 105051.

Cole, R., M. Brockhaus, G.Y. Wong, M.H. Kallio, and M. Moeliono. 2019. Local agency in development, market, and forest conservation interventions in Lao PDR's northern uplands. Southeast Asian Studies 8: 173-202.

Cole, R., G. Wong, M. Brockhaus, M. Moeliono, and M. Kallio. 2017a. Objectives, ownership and engagement in Lao PDR's REDD+ policy landscape. Geoforum 83: 91-100.

Curtis, P.G., C.M. Slay, N.L. Harris, A. Tyukavina, and M.C. Hansen. 2018. Classifying drivers of global forest loss. Science 361: $1108-1111$

Dauvergne, P. 1993. The politics of deforestation in Indonesia. Pacific Affairs 66: 497-518. https://doi.org/10.2307/2760676.

Dawson, N.M., M. Mason, J.A. Fisher, D.M. Mwayafu, H. Dhungana, H. Schroeder, and M. Zeitoun. 2018. Norm entrepreneurs sidestep REDD+ in pursuit of just and sustainable forest governance. Sustainability 10: 1726.

Delabre, I., E. Boyd, M. Brockhaus, W. Carton, T. Krause, P. Newell, and F. Zelli. 2020. Unearthing the myths of global sustainable forest governance. Global Sustainability. https://doi.org/10. 1017/sus.2020.11.

Di Gregorio, M., M. Brockhaus, T. Cronin, and E. Muharrom. 2012. Politics and power in national REDD+ policy processes. In Analysing REDD+: Challenges and choices, ed. A. Angelsen, M. Brockhaus, W.D. Sunderlin, and L. Verchot, 69-90. Bogor: CIFOR.

Di Gregorio, M., M. Brockhaus, T. Cronin, E. Muharrom, S. Mardiah, and L. Santoso. 2015a. Deadlock or transformational change? Exploring public discourse on REDD+ across seven countries. Global Environmental Politics 15: 63-84.

Di Gregorio, M., M. Brockhaus, T. Cronin, E. Muharrom, L. Santoso, S. Mardiah, and M. Buedenbender. 2013. Equity and REDD plus 
in the Media: A comparative analysis of policy discourses. Ecology and Society 18: 39.

Di Gregorio, M., L. Fatorelli, J. Paavola, B. Locatelli, E. Pramova, D.R. Nurrochmat, P.H. May, M. Brockhaus, et al. 2019. Multilevel governance and power in climate change policy networks. Global Environmental Change 54: 64-77.

Di Gregorio, M., L. Fatorelli, E. Pramova, P. May, B. Locatelli, and M. Brockhaus. 2016. Integrating mitigation and adaptation in climate and land use policies in Brazil: A policy document analysis, CCCEP Working Paper 57, Centre for Climate Change Economics and Policy (CCCEP), University of Leeds, Leeds, UK.

Di Gregorio, M., C.T. Gallemore, M. Brockhaus, L. Fatorelli, and E. Muharrom. 2017a. How institutions and beliefs affect environmental discourse: Evidence from an eight-country survey on REDD+. Global Environmental Change 45: 133-150.

Di Gregorio, M., D.R. Nurrochmat, L. Fatorelli, E. Pramova, I.M. Sari, B. Locatelli, and M. Brockhaus. 2015b. Integrating mitigation and adaptation in climate and land use policies in Indonesia: A policy document analysis. CCCEP Working Paper 245, Centre for Climate Change Economics and Policy (CCCEP), University of Leeds, Leeds, UK.

Di Gregorio, M., D.R. Nurrochmat, J. Paavola, I.M. Sari, L. Fatorelli, E. Pramova, B. Locatelli, M. Brockhaus, et al. 2017b. Climate policy integration in the land use sector: Mitigation, adaptation and sustainable development linkages. Environmental Science \& Policy 67: 35-43.

Djoudi, H., and M. Brockhaus. 2011. Is adaptation to climate change gender neutral? Lessons from communities dependent on livestock and forests in northern Mali. International Forestry Review 13: 123-135.

Djoudi, H., and M. Brockhaus. 2016. Unveiling the complexity of gender and adaptation: The "feminization" of forests as a response to drought-induced men's migration in Mali. Gender and Forests: Climate Change, Tenure, Value Chains and Emerging Issues. https://doi.org/10.4324/9781315666624.

Djoudi, H., M. Brockhaus, and B. Locatelli. 2013. Once there was a lake: Vulnerability to environmental changes in northern Mali. Regional Environmental Change 13: 493-508.

Djoudi, H., B. Locatelli, C. Vaast, K. Asher, M. Brockhaus, and B.B. Sijapati. 2016. Beyond dichotomies: Gender and intersecting inequalities in climate change studies. Ambio 45: 248-262. https://doi.org/10.1007/s13280-016-0825-2.

Domínguez, L., and C. Luoma. 2020. Decolonising conservation policy: How colonial land and conservation ideologies persist and perpetuate indigenous injustices at the expense of the environment. Land 9: 65.

Doolittle, A. 2003. Colliding discourses: Western land laws and native customary rights in North Borneo, 1881-1918. Journal of Southeast Asian Studies. https://doi.org/10.1017/ S0022463403000067.

Dove, M.R. 1983. Theories of swidden agriculture, and the political economy of ignorance. Agroforestry Systems 1: 85-99. https:// doi.org/10.1007/BF00596351.

Dressler, W.H., D. Wilson, J. Clendenning, R. Cramb, R. Keenan, S. Mahanty, T.B. Bruun, O. Mertz, et al. 2017. The impact of swidden decline on livelihoods and ecosystem services in Southeast Asia: A review of the evidence from 1990 to 2015. Ambio 46: 291-310. https://doi.org/10.1007/s13280-016-0836-Z

Enrici, A., and K. Hubacek. 2016. Business as usual in Indonesia: Governance factors effecting the acceleration of the deforestation rate after the introduction of REDD+. Energy, Ecology and Environment 1: 183-196.

Ferrante, L., and P.M. Fearnside. 2020. The Amazon: Biofuels plan will drive deforestation. Nature 577: 170-170.
Forsyth, T., and A. Walker. 2008. Forest guardians, forest destroyers: The politics of environmental knowledge in northern Thailand. Washington: University of Washington Press.

Foucault, M. 1978. The history of sexuality. An introduction, vol 1. New York: Pantheon Books.

Galaz, V., B. Crona, A. Dauriach, B. Scholtens, and W. Steffen. 2018. Finance and the earth system-exploring the links between financial actors and non-linear changes in the climate system. Global Environmental Change 53: 296-302.

Gebara, M.F., P. Gallo, A. Brites, G. Lima, and T. Micheletti. 2020. The pluriversality of efforts to reduce deforestation in Brazil over the past decade: An analysis of policy actors' perceptions. Forests 11: 1061

Global Wittness. 2019. Defending Tomorrow. The climate crisis and threats against land and environment. Report.

Hankivsky, O. 2014. Intersectionality 101, 1-34. Canada: The Institute for Intersectionality Research \& Policy, SFU.

Harris, N.L., D.A. Gibbs, A. Baccini, R.A. Birdsey, S. De Bruin, M. Farina, L. Fatoyinbo, M.C. Hansen, et al. 2021. Global maps of twenty-first century forest carbon fluxes. Nature Climate Change 11: $234-240$.

Ingalls, M.L., P. Meyfroidt, P.X. To, M. Kenney-Lazar, and M. Epprecht. 2018. The transboundary displacement of deforestation under REDD+: Problematic intersections between the trade of forest-risk commodities and land grabbing in the Mekong region. Global Environmental Change 50: 255-267.

IPCC, 2007. Climate Change 2007: Synthesis Report. Contribution of Working Groups I, II and III to the Fourth Assessment Report of the Intergovernmental Panel on Climate Change.

Juhola, S., E. Glaas, B.O. Linnér, and T.S. Neset. 2016. Redefining maladaptation. Environmental Science \& Policy 55: 135-140.

Kaisa, K.K., B. Maria, M. Efrian, J. Sirkku, M. Moira, M. Cynthia, and D. Bimo. 2017. Analyzing REDD+ as an experiment of transformative climate governance: Insights from Indonesia. Environmental Science \& Policy 73: 61-70.

Kallio, M.H., N.J. Hogarth, M. Moeliono, M. Brockhaus, R. Cole, I. Waty Bong, and G.Y. Wong. 2019. The colour of maize: Visions of green growth and farmers perceptions in northern Laos. Land Use Policy 80: 185-194. .

Karambiri, M., and M. Brockhaus. 2019. Leading rural land conflict as citizens and leaving it as denizens: Inside forest conservation politics in Burkina Faso. Journal of Rural Studies 65: 22-31.

Klinsky, S., T. Roberts, S. Huq, C. Okereke, P. Newell, P. Dauvergne, K. O'Brien, H. Schroeder, et al. 2017. Why equity is fundamental in climate change policy research. Global Environmental Change 44: 170-173.

Korhonen-Kurki, K., J. Sehring, M. Brockhaus, and M. Di Gregorio. 2014. Enabling factors for establishing REDD+ in a context of weak governance. Climate Policy 14: 167-186. https://doi.org/ 10.1080/14693062.2014.852022.

Korhonen-Kurki, K., M. Brockhaus, J. Sehring, M. Di Gregorio, S. Assembe-Mvondo, A. Babon, M. Bekele, V. Benn, et al. 2019. What drives policy change for REDD+? A qualitative comparative analysis of the interplay between institutional and policy arena factors. Climate Policy 19: 315-328. https://doi.org/10. 1080/14693062.2018.1507897.

Kroeger, M. 2020. Deforestation, cattle capitalism and neodevelopmentalism in the Chico Mendes Extractive Reserve, Brazil. The Journal of Peasant Studies 47: 464-482.

Kroeger, M., and A. Nygren. 2020. Shifting frontier dynamics in Latin America. Journal of Agrarian Change. https://doi.org/10. 1111/joac.12354.

Kröger, M. 2016. The political economy of 'flex trees': A preliminary analysis. Journal of Peasant Studies. https://doi.org/10.1080/ 03066150.2016 .1140646$. 
Li, T.M. 2007. Practices of assemblage and community forest management. Economy and Society 36: 263-293. https://doi.org/ 10.1080/03085140701254308.

Liao, C., A. Agrawal, P.E. Clark, S.A. Levin, and D.I. Rubenstein. 2020. Landscape sustainability science in the drylands: Mobility, rangelands and livelihoods. Landscape Ecology 35: 1-15.

Locatelli, B., M. Kanninen, M. Brockhaus, C.J.P. Colfer, D. Murdiyarso, and H. Santoso. 2008. Facing an uncertain future: how forest and people can adapt to climate change. Bogor: CIFOR.

Locatelli, B., C. Pavageau, E. Pramova, and M. Di Gregorio. 2015. Integrating climate change mitigation and adaptation in agriculture and forestry: Opportunities and trade-offs. Wiley Interdisciplinary Review Climate Change 6: 585-598.

Loft, L., D.N. Le, T.T. Pham, A.L. Yang, J.S. Tjajadi, and G.Y. Wong. 2017. Whose equity matters? National to local equity perceptions in Vietnam's payments for forest ecosystem services scheme. Ecological Economics. https://doi.org/10.1016/j. ecolecon.2017.01.016.

Lund, J.F., E. Sungusia, M.B. Mabele, and A. Scheba. 2017. Promising change, delivering continuity: REDD+ as conservation fad. World Development 89: 124-139.

Maharani, C.D., M. Moeliono, G.Y. Wong, M. Brockhaus, R. Carmenta, and M. Kallio. 2019. Development and equity: A gendered inquiry in a swidden landscape. Forest Policy and Economics 101: 120-128.

Martin, A., M. Teresa Armijos, B. Coolsaet, N. Dawson, G.A.S. Edwards, R. Few, N. Gross-Camp, I. Rodriguez, H., et al. 2020. Environmental justice and transformations to sustainability. Environment: Science and Policy for Sustainable Development 62: 19-30. https://doi.org/10.1080/00139157.2020.1820294.

McCarthy, S., and L. Tacconi. 2011. The political economy of tropical deforestation: Assessing models and motives. Environmental Politics 20: 115-132.

Menton, M., C. Larrea, S. Latorre, J. Martinez-Alier, M. Peck, L. Temper, and M. Walter. 2020. Environmental justice and the SDGs: From synergies to gaps and contradictions. Sustainability Science. https://doi.org/10.1007/s11625-020-00789-8.

Moeliono, M., M. Brockhaus, C.T. Gallemore, D. Bimo, M. Cynthia, M. Efrian, and T.T. Pham. 2020. REDD+ in Indonesia: A new mode of governance or just another project? Forest Policy and Economics 121: 102316.

Moeliono, M., T.T. Pham, I.W. Bong, G.Y. Wong, and M. Brockhaus. 2017. Social forestry: Why and for whom? A comparison of policies in Vietnam and Indonesia. Forest and Society 1: 78-97. https://doi.org/10.24259/fs.v1i2.2484.

Myers, R., A.M. Larson, A. Ravikumar, L.F. Kowler, A. Yang, and T. Trench. 2018. Messiness of forest governance: How technical approaches suppress politics in REDD+ and conservation projects. Global Environmental Change 50: 314-324. https:// doi.org/10.1016/j.gloenvcha.2018.02.015.

Newell, P. 2005. Race, Class and the Global Politics of Environmental Inequality. Global Environmental Politics 5: 70.

Newell, P., and D. Mulvaney. 2013. The political economy of the 'just transition.' The Geographical Journal 179: 132-140.

NYDF Assessment Partners. 2020. Balancing forests and development: Addressing infrastructure and extractive industries, promoting sustainable livelihoods. Climate Focus (coordinator and editor).

Peluso, N.L., and C. Lund. 2001. New frontiers of land control: Introduction. Journal of Peasant Studies 38: 667-681.

Peluso, N.L., and P. Vandergeest. 2020. Writing political forests. Antipode 52: 1083.

Pereira, E.J.D.A.L., P.J.S. Ferreira, L.C. de Santana Ribeiro, T.S. Carvalho, and H.B. de Barros Pereira. 2019. Policy in Brazil
(2016-2019) threaten conservation of the Amazon rainforest. Environmental Science \& Policy 100: 8-12.

Pham, T.T., M. Moeliono, T.H. Nguyen, H.T. Nguyen, and T.H. Vu. 2019. The context of REDD+ in Vietnam: Drivers, agents and institutions, 2nd ed. Occasional Paper 75. Bogor: CIFOR.

Pham, T.T., H.C. Ngo, T.L.C. Dao, T.L. Hoang, and M. Moeliono. 2021b. Participation and influence of REDD+ actors in Vietnam, 2011-2019. Global Environmental Change 68: 102249.

Pham, T.T., N.L.D. Tran, N. Nong Nguyen Khanh, and T. Nguyen Dinh. 2021a. Mainstreaming gender in REDD+ policies and projects in 17 countries. Journal of Environmental Policy \& Planning. https://doi.org/10.1080/1523908X.2021.1903408.

Redclift, M. 1997. Development and global environmental change. Journal of International Development: THe Journal of the Development Studies Association 9: 391-401.

Redclift, M., and C. Sage. 1998. Global environmental change and global inequality: North/South perspectives. International Sociology 13: 499-516.

Ribot, J.C., A. Agrawal, and A.M. Larson. 2006. Recentralizing while decentralizing: How national governments reappropriate forest resources. World Development 34: 1864-1886.

Rowley, C., R.D. Tollison, and G. Tullock, eds. 2013. The political economy of rent-seeking, vol. 1 . New York: Springer.

Roy, A. 2012. Histoire des représentations paysannes au Mali (Doctoral dissertation, Thèse d'anthropologie. École des hautes études en sciences sociales, Paris).

Rudel, T.K. 2007. Changing agents of deforestation: From stateinitiated to enterprise driven processes, 1970-2000. Land Use Policy 24: 35-41.

Sahide, M., M. Fisher, S. Supratman, Y. Yusran, A.A. Pratama, A. Maryudi, Y. Runtuboi, A. Sabar, et al. 2020. Prophets and profits in Indonesia's social forestry partnership schemes: Introducing a sequential power analysis. Forest Policy and Economics. https:// doi.org/10.1016/j.forpol.2020.102160.

Salvini, G., M. Herold, V. De Sy, G. Kissinger, M. Brockhaus, and M. Skutsch. 2014. How countries link REDD+ interventions to drivers in their readiness plans: Implications for monitoring systems. Environmental Research Letters. https://doi.org/10. 1088/1748-9326/9/7/074004.

Scheidel, A., D. Del Bene, J. Liu, G. Navas, S. Mingorría, F. Demaria, S. Avila, and B. Roy. 2020. Environmental conflicts and defenders: A global overview. Global Environmental Change 63: 102104 .

Scheidel, A., and A.H. Sorman. 2012. Energy transitions and the global land rush: Ultimate drivers and persistent consequences. Global Environmental Change 22: 588-595.

Scoones. 2021. Pastoralists and peasants: Perspectives on agrarian change. The Journal of Peasant Studies 48: 1-47. https://doi.org/ 10.1080/03066150.2020.180224.

Scoones, I., M. Leach, and P. Newell, eds. 2015. The politics of green transformations. London: Routledge.

Seymour, F., and J. Busch. 2016. Why forests? Why now?: The science, economics, and politics of tropical forests and climate change. Washington: Brookings Institution Press.

Skutsch, M., and E. Turnhout. 2020. REDD+: If communities are the solution, what is the problem? World Development. https://doi. org/10.1016/j.worlddev.2020.104942.

Temper, L., M. Walter, I. Rodriguez, A. Kothari, and E. Turhan. 2018. A perspective on radical transformations to sustainability: Resistances, movements and alternatives. Sustainability Science 13: 747-764.

Thaler, G.M., C. Viana, and F. Toni. 2019. From frontier governance to governance frontier: The political geography of Brazil's Amazon transition. World Development 114: 59-72. https://doi. org/10.1016/j.worlddev.2018.09.022. 
Thu, T.P., M. Moeliono, M. Brockhaus, G.Y. Wong, and N.D. Le. 2020. The politics of swidden: A case study from Nghe An and Son La in Vietnam. Land Use Policy 99: 103050. https://doi.org/ 10.1016/j.landusepol.2017.10.057.

Turner, M.D. 2011. The new pastoral development paradigm: Engaging the realities of property institutions and livestock mobility in dryland Africa. Society and Natural Resources 24: 469-484.

Wong, G.Y., C. Luttrell, L. Loft, A. Yang, T.T. Pham, D. Naito, S. Assembe-Mvondo, and M. Brockhaus. 2019. Narratives in REDD + benefit sharing: Examining evidence within and beyond the forest sector. Climate Policy. https://doi.org/10.1080/ 14693062.2019.1618786.

Wong, G.Y., M. Moeliono, T.T. Pham, I.W. Bong, M.A.K. Sahide, D. Naito, and M. Brockhaus. 2020. Social forestry in Southeast Asia: Evolving interests, discourses and the many notions of equity. Geoforum 117: 246-258.

Xu, Z., Y. Li, S.N. Chau, T. Dietz, C. Li, L. Wan, J. Zhang, L. Zhang, et al. 2020. Impacts of international trade on global sustainable development. Nature Sustainability. 3: 964-971.

Ziegler, A.D., J.M. Fox, E.L. Webb, C. Padoch, S.J. Leisz, R.A. Cramb, O. Mertz, T.B. Bruun, et al. 2011. Recognizing contemporary roles of swidden agriculture in transforming landscapes of Southeast Asia. Conservation Biology 25: 846-848. https://doi.org/10.1111/j.1523-1739.2011.01664.x.

Publisher's Note Springer Nature remains neutral with regard to jurisdictional claims in published maps and institutional affiliations.

\section{AUTHOR BIOGRAPHIES}

Maria Brockhaus $(\square)$ is Professor and Chair of International Forest Policy at the University of Helsinki, and a member of HELSUS, the University's Sustainability Centre. Her main research themes are forest policy and governance in climate change mitigation and adaptation, the political economy of tropical deforestation, policy and institutional change and related policy networks and discourses. Address: Department of Forest Science, Chair of International Forest Policy, University of Helsinki (Helsinki) and Helsinki Sustainability Center (HELSUS), Helsinki, Finland.

Address: CIFOR, Bogor, Indonesia.

Address: Research Institute for Humanity and Nature, Kyoto, Japan. e-mail: Maria.Brockhaus@Helsinki.fi
Monica Di Gregorio is an Associate Professor of Environmental Politics and Governance at the Sustainability Research Institute at the University of Leeds. Her research focuses on land use and climate politics in the tropics, and in particular mitigation, adaptation and sustainable development linkages. She is particularly interested in environmental policy networks and contentious environmental politics in the Global South.

Address: Sustainability Research Institute, School of Earth and Environment, University of Leeds, Leeds, UK.

Houria Djoudi is Senior Scientist at the Center for International Forestry Research (CIFOR), Bogor, Indonesia. Houria's work focuses on socio-ecological systems analysis at the interface of environmental and institutional changes. She has carried out research on adaptation to climate change within silvo-pastoral system with an intersectionality lens.

Address: CIFOR, Bogor, Indonesia.

Moira Moeliono is Senior Associate and consultant at the Center for International Forestry Research (CIFOR), Bogor, Indonesia. She has been involved both in the Global Comparative Study on REDD+ looking at national policies and in the ASEAN Swiss Partnership for Social Forestry and Climate Change. Her current research focuses on land use changes and social forestry in the context of climate change, mostly in South East Asia.

Address: CIFOR, Bogor, Indonesia.

Address: Research Institute for Humanity and Nature, Kyoto, Japan.

Thuy Thu Pham is Senior Scientist at Center for International Forestry Research and a member of Vietnamese National Payment for Forest Environmental Services network. Her main research themes are payment for environmental services, forest governance and climate change policies.

Address: CIFOR, Bogor, Indonesia.

Grace Y. Wong is a researcher at the Stockholm Resilience Centre of Stockholm University and an Associate Professor at the Research Institute for Humanities and Nature in Kyoto, Japan. Her current research is on issues of social and environmental justice in changing forest-agriculture frontiers, with a particular emphasis on the politics of land and access, precarity and agency.

Address: Research Institute for Humanity and Nature, Kyoto, Japan. Address: Stockholm Resilience Centre, Stockholm University, Stockholm, Sweden. 